\title{
ÍNDICE DE FIGURAS Y TABLAS
}

\section{FIGURAS}

1. Necrópolis celtibéricas excavadas entre 1905 y 1985 (A) y distribución de tumbas y conjuntos cerrados obtenidos en el mismo período (B). Proporción de conjuntos cerrados respecto al total de tumbas excavadas en algunas de las principales necrópolis celtibéricas (C). (A-B, según Álvarez-Sanchís 1990)

2. Localización de la Celtiberia en la Europa descrita por Estrabón (según Lasserre 1966)

3. El territorio de los Belos y de los Lusones, estos últimos, según Apiano (1) y según Estrabón y la toponimia (2). (Según Burillo 1986).

4. Hispania y las ciudades de Pelendones, Arévacos y Celtíberos según Ptolomeo. (Según Tovar 1976) .....

5. Áreas lingüísticas de la Península Ibérica. (Según Untermann 1981)

6. A, topónimos en -briga: 1, indígenas; 2 , latinos. B, antropónimos y etnónimos Celtius y Celtiber y relacionados: 1-3, área linguística del celtibérico, según diversos autores; 4 , Celtius y variantes; 5 , Celtiber, $-a$; 6, Celtitanus, $-a ; 7$, Celtiqum; 8, etnónimos Celtici; 9, ciudades de los Celtici del Suroeste y ciudades localizadas de la Celtiberia; 10, «Celtigos» en la toponimia actual; 11, inscripciones lusitanas. (B, según Almagro-Gorbea 1993)

7. A, antropónimos Ambatus y relacionados: B, grupos familiares (1) y castella (2). (A, según Albertos 1976, modificado y ampliado; B, según Albertos 1975, ampliado)

8. Mapas de dispersión de las fíbulas de caballito (con jinete y simples) (A) y de los puñales biglobulares (B). (A, según Almagro-Gorbea y Torres e.p., modificado)

9. Mapa de localización del área estudiada

10. Zonas agroclimáticas

11. Usos agropecuarios y forestales.

12. Localización de yacimientos e indicios minerales

13. Perfiles topográficos de algunos asentamientos de la comarca de Daroca (Jiloca Medio-Alto Huerva). (Según Burillo, dir. 1993)

14. Comparación entre las superficies de los hábitats de diferentes áreas de la Celtiberia

15. Ciudades celtibéricas de superficie conocida

16. Plantas del oppidum de Contrebia Carbica y de algunas de las más importantes ciudades celtibéricas. (Según Mena et alii 1988, Schulten 1933a, Taracena 1926b y 1941 y Vicente et alii 1991)

17. Plantas de algunos castros de la serranía soriana. (Según Taracena 1926a y 1929, Ruiz et alii 1985, Bachiller 1987a y González, en Morales 1995)

18. Alzado de algunas murallas celtibéricas. (Según Sanmiguel et alii 1992, Arlegui 1992b, Iglesias et alii 1989 y Hernández Vera 1982) 
19. 1, sección de la muralla de El Castillo de las Espinillas de Valdeavellano de Tera; 2, corte de la muralla de El Castillo de Arévalo de la Sierra; 3, sección y planta de la muralla con paramentos internos de Los Castellares de Suellacabras; 4, muralla con paramentos internos de Los Castejones de Calatañazor (fig. 20,4); 5, secciones de diversos tramos de la muralla de Ocenilla (fig. 23,1). (Según Taracena 1929 (1), 1926 a (2-4), y $1932(5))$

20. Plantas de los poblados de Los Villares de Ventosa de la Sierra (1), Cerro Ontalvilla, en Carbonera de Frentes (2), Castillejo de Golmayo (3), Los Castejones de Calatañazor (4), Los Castellares de Suellacabras (5). (Según González, en Morales 1995 (1-3) y Taracena 1926a (4-5))

21. 1, planta y perfil de El Castillo de las Espinillas de Valdeavellano de Tera (según Taracena 1929), con indicación del posible acceso (según Hogg 1957) y la localización de los torreones (según Ruiz Zapatero 1977); 2, sección y planta de la torre I (según Ruiz Zapatero 1977)

22. Planta del poblado de Castilmontán (1) y detalle de su sector occidental (2). (Según Arlegui 1992b) .......

23. Plantas de El Castillo de Ocenilla (1) y de El Molôn de Camporrobles (2). (Según Taracena 1932 (1) y Almagro-Gorbea et alii 1996 (2))

24. 1, detalle de la puerta Sureste de EI Castillo de Ocenilla y escalera del cuerpo de guardia (departamento 6) de la misma; 2, acceso a través del cuerpo de la muralla de Los Castejones de Calatañazor (fig. 20,4). (Según Taracena 1932 (1) y 1926a (2))

25. Plantas de las ciudades celtibérico-romanas de Termes (1) y Segobriga (2). (Según Taracena 1954 (1) y Almagro-Gorbea y Lorrio 1989 (2))

26. Planta y sección de las defensas de La Cava (1). Sección de la muralla y foso de Contrebia Leukade (2). (Según Iglesias et alii 1989 (1) y Taracena 1954 (2)).

27. Dispersión de los castros con piedras hincadas en la Península Ibérica (1) y secciones de las defensas de El Castillejo de Castilfrío de la Sierra (2), El Castillo de las Espinillas de Valdeavellano de Tera (3), El Castillejo de Langosto (4) y El Castillejo de Hinojosa de la Sierra (5). (Según Almagro-Gorbea 1994 (1) y Taracena $1929(2-5), n^{\circ} 4$ modificado)

28. Planos de los castros de Guijosa (1) y Hocincavero (2). (Según Belén et alii 1978 (1) y Barroso y Díez $1991(2))$

29. Planta y perfil de las cabañas circulares de la fase inicial de El Castillejo de Fuensaúco. (Según Romero y Misiego 1992 y 1995b)

30. 1, viviendas rectangular y circular —en línea discontinua - del segundo nivel de ocupación de El Castillejo de Fuensaúco; 2, planta de las viviendas superpuestas del castro del Zarranzano. (Según Romero y Misiego 1995b (1) y Romero 1989 (2))

31. Reconstrucción de las viviendas A (1) y B (2) de la fase I de El Ceremeño y del poblado de Castilmontán (3). (Según Cerdeño et alii 1995a (1), Cerdeño 1995 (2) y Arlegui 1990b (3)) .

32. 1, reconstrucción del trazado urbano de las dos fases del poblado de El Ceremeño. 2, detalle de un sector del poblado del Alto Chacón. (Según Cerdeño et alii 1993-95 (1) y Atrián 1976 (2)).

33. Plano de la insula de La Caridad de Caminreal donde se localiza la Casa de Likine (1) y detalle de la misma (2) (según Burillo, dir. 1991 (1) y Vicente 1988 (2)), con la distribución de áreas funcionales (según Vicente et alii 1991).

34. Numancia: casa celtibérica (1) y reconstrucción de algunas manzanas y casas de la ciudad romana (2). (Según Schulten 1931 (1) y Jimeno 1994a (2))

35. Contrebia Leukade: conjunto de viviendas rupestres del sector II-LL (1) y planta de la ciudad (2). (Según Hernández Vera 1982)

36. Plantas de Los Castellares de Herrera de los Navarros (1), el Castillo de Arévalo de la Sierra (2), con indicación de los accesos (según González, en Morales 1995), el Castillejo de Taniñe (3) y Castilterreño de Izana (4). (Según Burillo y de Sus 1986 (1), Taracena 1926a (2-3) y 1927 (4))

37. Numancia: plano de la ciudad y de la superposición de las ciudades celtibérica (puntos) y romana (línea). (Según Schulten 1933b y Taracena 1954). 
38. Plano de dos sectores de la ciudad de Segontia Lanka. (Según Taracena 1929 y 1932)

39. Contrebia Belaisca: 1, plano de la acrópolis y reconstrucción hipotética de los elementos arquitectónicos de arenisca localizados en la zona norte del gran edificio de adobe; 2, casa señorial e instalaciones agrícolas de transformación de la zona baja de la ciudad, con la indicación $\left(^{*}\right)$ del lugar de aparición del bronce de Botorrita 1. (Según Beltrán 1987b)

40. Localización de las necrópolis de Aguilar de Anguita (1), Almaluez (2), Osonilla (3), La Revilla de Calatañazor (4), Ucero (5) y Gormaz (6) y los poblados con ellas relacionados

41. Localización de las necrópolis de los oppida de Numancia (1), Uxama (2), Termes (3) y Luzaga (4). (Según Jimeno y Morales 1993 (1), Campano y Sanz 1990 (2) y Argente 1994 (3))

42. La ordenación del espacio funerario en las necrópolis celtibéricas: A, tumbas con estelas formando calles; $\mathrm{B}$, idem sin estelas; $\mathrm{C}$, tumbas sin orden aparente, con estelas; $\mathrm{D}$, idem sin estelas; $\mathrm{E}$, idem con túmulos; $\mathrm{F}$, sin datos

43. Necrópolis de Alpanseque: 1, plano de la primera campaña de excavaciones (1915); 2, interpretación de la misma (la zona rayada corresponde al prado donde se realizaron las excavaciones de 1916). (1, según Cabré 1917)

44. Plano de la necrópolis de La Requijada de Gormaz. (Según Morenas de Tejada)

45. Plano y perfiles de la zona 4 de la necrópolis de Riba de Saelices. (Según Cuadrado 1968, modificado)..

46. 1, plano de la necrópolis de Monteagudo de las Vicarías. 2, articulación interna a partir de los tipos de ajuares de la necrópolis de El Altillo de Cerropozo (Atienza). (1, según Taracena 1932)

47. 1, articulación social de la necrópolis de La Mercadera a partir del grado de complejidad de los ajuares. 2, Plano de la necrópolis de Numancia con la identificación de dos grupos de tumbas a partir del contenido de sus ajuares. (Según Lorrio 1990, modificado (1) y Jimeno 1996 (2)).

48. 1, plano de la necrópolis de La Yunta, con la distribución de los enterramientos por sexos. 2, plano de un sector de la necrópolis de Las Madrigueras, en Carrascosa del Campo. (Según García Huerta y Antona 1992, modificado (1) y Almagro-Gorbea 1969 (2))

49. 1, modelo general del conjunto de pautas relacionadas con la práctica funeraria, a partir de ejemplos etnográficos europeos; 2, modelo de ritual funerario para el ámbito celtibérico. (1, según Bartel 1982, tomado de Ruiz Zapatero y Chapa 1990; 2, según Burillo 1991a).

50. Planta y alzado de la tumba 36 de la necrópolis de Numancia (1). Reconstrucción ideal de una tumba celtibérica (2). Estela funeraria con decoración figurada de Aguilar de Anguita (3). (Según Jimeno y Morales 1994 (1) y Aguilera 1913b (3))

51. Sigüenza: planos parciales de las fases I, campaña de 1976 (1), y II, campaña de 1974 (2). (Según Cerdeño y Pérez de Ynestrosa 1993 (1), modificado, y Fernández-Galiano et alii 1982 (2))

52. 1, planta y sección del túmulo 3 de Pajaroncillo; 2, planta de la necrópolis de Alconchel de la Estrella. (Según Almagro-Gorbea 1973 (1) y Millán 1990 (2))

53. La Mercadera: 1, presencia de metales por tipos de tumbas; 2 , distribución de algunos elementos presentes en los ajuares por tipos de tumbas. (Según Lorrio 1990, modificado (2))

54. Dendrograma del análisis de conglomerados de los ajuares de la necrópolis de La Mercadera, según el método de Ward, con distancia «city block»

55. Distribución de la «riqueza» en algunas necrópolis del grupo del Alto Tajo-Alto Jalón

56. Distribución de la «riqueza» en algunas necrópolis del Alto Duero

57. Las fuentes fundamentales para el estudio del armamento de los Celtíberos

58. Conjuntos cerrados identificados en las principales necrópolis celtibéricas, con mención, en la parte superior de cada histograma, del número total de sepulturas excavadas en cada caso

59. Cuadro evolutivo de la panoplia celtibérica .........

60. Fase I (siglo VI a.C.). Necrópolis con armas 
61. Fase I: A, Sigüenza, tumba 1; B, Sigüenza-15; C, Sigüenza-14; D, Atienza-7; E, Carratiermes-549; F, Carratiermes-639; G, Carratiermes-582; H, La Mercadera-83; I, La Mercadera-67. (Según Cerdeño 1979 (A), Cerdeño 1981 (B), Cabré 1930 (C), Argente et alii 1991a (D-F) y Schüle 1969 (G-H))

62. Fase II (siglos V-III a.C.). Necrópolis con armas en el Alto Duero-Alto Tajo-Alto Jalón ...

63. Alto Tajo-Alto Jalón: Subfase IIA. Tumba A de Aguilar de Anguita. (Según Schüle 1969)

64. Alto Tajo-Alto Jalón: Subfase IIA. Aguilar de Anguita. A, tumba B; B, diversos modelos de espadas; C, tumba 1. (Según Schüle 1969 (A-B) y Cabré 1939-40 (C))

65. Alto Tajo-Alto Jalón: Subfase IIA. Alpanseque. Tumbas 20, calle III (A), 12, calle II (B) y A (C). (Según Cabré 1939-40)

66. Alto Tajo-Alto Jalón: Subfase IIA. A, Griegos-3; B, Alpanseque-27, calle II; C, Alpanseque-10 (calle II); D, Sigüenza-29. (Según Cabré 1939-40 (A), Schüle 1969 (A-C) y Cerdeño y Pérez de Ynestrosa 1993 (D)) .

67. Alto Tajo-Alto Jalón: Subfase IIA. Atienza. Tumbas 1 (A), 3 (B), 5 (C), 6 (D), 9 (E), 10 (F), 12 (G) y 13 (H). (Según Cabré 1930) .

68. Alto Tajo-Alto Jalón: Subfases IIA-IIB. Atienza. Tumbas 15 (A) y 16 (B), (Según Cabré 1930)

69. Alto Tajo-Alto Jalón: Subfase IIB. Arcobriga. Tumbas A (A), C (B), B (C) y D (D). El Atance. Tumbas 28 (E) y 12 (F). (Según Schüle 1969)

70. Combinaciones de armas en la necrópolis de La Mercadera

71. Alto Duero: Subfase IIA. La Mercadera. Tumbas 91 (A), 15 (B), 19 (C), 40 (D), 68 (E), 52 (F) y 78 (G). (Según Taracena 1932 (A y C), Cabré 1939-40 (B y F) y Schüle 1969 (D-E y G))

72. Alto Duero: Subfases IIA (A-B) y IIB (C-D). Quintanas de Gormaz. Tumbas AA (A), A (B), D (C), R (D) y $\tilde{N}$ (E). (Según Schüle 1960 (AA), Cabré 1990 (B), Lenerz-de Wilde 1991 (C) y Schüle 1969 (D-E)) ....

73. Mapa de distribución de las vainas latenienses decoradas con liras y dragones: (*) Quintanas de Gormaz. (Según Ginoux 1995)

74. Alto Duero: Subfases IIA-IIB. La Revilla. Tumbas A (A), B (B) y C (C). Gormaz. Tumba 10 (D). (Según Ortego 1983 (A-C) y Cabré 1939-40 (D)).

75. Alto Duero: Subfase IIB-III. Osma (M.A.B.). Tumbas 1 (A), 2 (B), 3 (C), 4 (D), 7 (E) y 8 (F). (Según Schüle 1969)

76. Alto Duero: Subfase IIB-III. Osma (M.A.B.). Tumbas 9 (A), 10 (B), 11 (C), 12 (D), 14 (E) y 13 (F). (Según Schüle 1969)

77. Fase III (siglos II-I a.C.). Hallazgos de armas en la Celtiberia histórica (A, hábitats; B, neçópolis; $\mathrm{C}$, campamentos romanos; $\mathrm{D}$, depósitos; $\mathrm{E}$, hallazgos aislados)

78. Fase III. Hallazgos de armas en necrópolis (A-B), hábitats (C) y tesoriljos (D). A, Osma-14 (M.A.N.); $B$, tumba 2 de Numancia; C, Numancia: 1-14, puñales y cuchillos; 15 estandarte; 16, trompa de guerra; D, Quintana Redonda. (A, según Lenerz-de Wilde 1991 y dibujado sobre fotografia; B, según Jimeno y Morales 1993; C, según Schüle 1969 (1-14), Schulten 1931, dibujado sobre fotografía (15) y Wattenberg 1963 (16); y D, según Pascual 1991).

79. Representaciones de guerreros en la cerámica pintada celtibérica. (Según Wattenberg 1963, García y Bellido 1969 y Taracena 1932)

80. Comparación de los diversos tipos de armas reproducidos en las monedas de la Celtiberia y del Alto Ebro con los correspondientes tipos arqueológicos.

81. 1-5, representaciones de jinetes: $1-2$, estelas funerarias; $3-5$ fíbulas; 6 , cerámica pintada. 7 , remate de lanza de carro con doble prótomo de caballo y toro. (Según García y Bellido (1), Abásolo y Marco 1995 (2), Lenerz-de Wilde 1991 (3 y 5), Cabré 1939-40 (4), Wattenberg 1963 (6) y Galán $1989-90$ (7))...

82. 1, anillo y cuentas de oro del túmulo 84 de Pajaroncillo; 2-3, La Mercadera: ajuar de plata de la sepultura 5 y fibula anular argéntea de tumba 7; 4, fíbula de plata de Numancia; 5-6, fibulas argénteas del tesoro de Driebes; 7, fíbula áurea de Cheste. (Según Almagro-Gorbea 1973 (1), Schüle 1969 y Taracena 1932 (2), Argente 1994 (3-4), San Valero 1945 (5-6) y Lenerz-de Wilde 1991 (7)) 
83. Tipología de las fibulas celtibéricas según Argente. Tipos 1 a 7. (Según Argente 1990 y 1994)

84. Tipología de las fíbulas celtibéricas según Argente. Tipos 8 y 9. (Según Argente 1990 y 1994)

85. A, tumba 291 de Carratiermes; B, diversos modelos de pectorales, adornos y fíbulas espiraliformes. (Según Argente et alii 1992 (A), Argente 1994 (B, 1-3, 6-7 y 11-12) y Schüle 1969 (B, 4-5 y 8-10)) ....

86. A, tumba 9 (calle I) de Alpanseque; B, «sepultura de dama celtibérica» de La Olmeda. (Según Cabré y Morán 1975b (A) y Schüle 1969 (B))

87. A, tumba 29 de Ucero; B, diversos modelos de pectorales de placa rectangular. (A, según García-Soto 1990. B, según Argente et alii 1992, Cerdeño 1976a, Lenerz-de Wilde 1991 y Cabré y Morán 1975a) .....

88. Combinaciones de los elementos de ajuar considerados como propios de tumbas femeninas en la necrópolis de La Mercadera. (Según Lorrio 1990)

89. Tipología de los broches de cinturón localizados en el territorio celtibérico

90. Tipología de los broches de cinturón localizados en el territorio celtibérico. Tipos A, B1 y B2. (Según Cerdeño 1978, Cabré 1937, Schüle 1969, Cerdeño 1977, Cerdeño et alii 1981, Almagro-Gorbea 1976-78 y Alonso 1992)

91. Tipología de los broches de cinturón localizados en el territorio celtibérico. Tipos B3 y B4. (Según Cerdeño 1977, Schüle 1969, Cerdeño 1978, Alonso 1992, Ortego 1985 y Taracena 1932)

92. Tipología de los broches de cinturón localizados en el territorio celtibérico: Tipos $\mathrm{C}$ y D. (Según Cerdeño 1977, Lenerz-de Wilde 1991, Schüle 1969, Ortego 1985, Cabré 1937, Idem 1930 y E. Cabré 1951

93. Distribución porcentual de los broches de cinturón identificados en la Meseta Oriental por tipos y ámbitos geográfico-culturales. (Con el grupo del Alto Tajo-Alto Jalón se han incluido los cementerios de Alpanseque y Carratiermes)

94. A-B, tumbas E y F de Arcobriga; C, La Mercadera-10 (el conjunto incluye otro brazalete similar al reproducido); D, sepultura 5 de Griegos; E, diversos elementos de bronce de la cultura castreña soriana. (Según Schüle 1969 (A-B y D), Taracena 1932 y Lenerz-de Wilde 1991 (C) y Romero 1991a (E)) ..........

95. A, diversos objetos de bronce (1-25) y pasta porosa (26-28) de la necrópolis de Molina de Aragón; B, supuesta diadema de la necrópolis de Clares. (Según Cerdeño et alii 1981 (A) y Barril y Dávila 1996 (B))

96. Numancia: adornos diversos (A) y simpula (B) de bronce. (Según Schüle 1969)

97. Placas omamentales de bronce de la necrópolis de Arcobriga ( $\mathrm{n}^{\circ} 10$ posible broche de cinturón). (Según Schüle 1969)

98. A, ajuar de una sepultura de Turmiel; B, diversos útiles procedentes de Numancia. (Según Barril 1993 (A) y Manrique 1980 (B))

99. Ajuar de la tumba 14 (calle I) de Alpanseque. (Según Cabré y Morán 1975b) .

100. Tabla de formas cerámicas de los castros sorianos. (Según Romero 1991a)

101. Alto Tajo-Alto Jalón: tabla de formas cerámicas a torno. (Según García Huerta 1990)

102. A, figuras zoomorfas de arcilla cocida del castro de Las Arribillas; B, representaciones zoomorfas en 'perspectiva cenital'. (1-2, aplicadas sobre cerámica; 3-4, pintadas; 5 , aplicada de plomo; 6 , tésera de hospitalidad de bronce; 7-8, fíbulas o posibles colgantes de bronce). (A, según Galán 1990. B, según Morales 1995 (1), Romero y Sanz 1992 (2, 5 y 6), Romero 1976a (3-4) y Schüle 1969 (7-8))

103. Coroplástica numantina. (Según Wattenberg 1963)

104. Reillo. Representaciones zoomorfas (1-2) e indeterminada (3) sobre cerámica y morillo rematado en cabeza de carnero (4). (Según Maderuelo y Pastor 1981)

105. 1-10, representaciones de cabezas humanas aplicadas sobre recipientes cerámicos. 11-13, cabezas exentas en cerámica. (Según García Merino 1992 (1-3), Saiz 1992 (4 y 11-12), Taracena 1943 (5), Hernández Vera y Sopeña 1991 (6), Wattenberg 1963 (7-9), Martínez Quirce 1996 y Morales 1984 (13))

106. Marcas sobre pesas de telar de Langa de Duero (1) y frecuencia de marcas y dispersión de medidas de peso de los ejemplares hallados en Numancia (2). (Según Taracena 1932 (1) y Arlegui y Ballano 1995 (2)) .... 
107. Pavimento de opus signinum de la Casa de Likine, en La Caridad de Caminreal. (Según Vicente et alii 1991)

108. Numancia: cerámicas monocromas y polícromas. (Según Wattenberg 1963)

109. Numancia. Representaciones figuradas pintadas sobre cerámica. (Según Romero 1976a (1-2) y Wattenberg $1963(3-9))$

110. Cuadro cronológico de los principales yacimientos datados de la Cultura Celtibérica por áreas geográfico culturales

111. Poblados y necrópolis de la fase inicial de la Cultura Celtibérica en el Alto Duero - Alto Tajo - Alto Jalón: A. necrópolis; B. poblados en altura sin evidencias de fortificaciones; C. idem en llano; D. poblados fortificados en altura; E. idem dudosos

112. Procedencia del ritual funerario y de los principales elementos característicos de las necrópolis de la fase inicial de la Cultura Celtibérica

113. Diagramas de los componentes formativos de la «cultura castreña soriana» y de las necrópolis celtibéricas. (Según Ruiz Zapatero, modificado) .

114. Comparación de las formas cerámicas características de los castros sorianos del Primer Hierro con las procedentes del Ebro Medio y del grupo Soto. (Según Ruiz Zapatero 1995)

115. Procedencia de algunos de los más destacados objetos del ámbito funerario característicos del Celtibérico Pleno

116. Evolución del poblamiento en diversos sectores del territorio celtibérico

117. Ciudades celtibéricas (siglos III-I a.C.) y principales vías romanas de la zona estudiada

118. Diversos instrumentos relacionados con las actividades agrícolas procedentes de Izana y Langa de Duero (siglo I a.C). (Según Barril 1992)

119. Distribución porcentual de restos faunísticos en algunos asentamientos celtibéricos. (Según diversos autores)

120. A, instrumentos relacionados con la siderurgia procedentes de Numancia y Langa de Duero; B, diversos instrumentos para el trabajo de la piel y las fibras textiles encontrados en Langa de Duero y Los Castejones de Calatañazor (siglo I a.C.). (Según Barril 1992)

121. Castro de El Royo: 1, estructura circular interpretada como un posible horno de fundición; 2, perfil Este de la cuadrícula donde apareció dicha estructura; 3, moldes de fundición. (Según Eiroa 1981)

122. Instrumentos para el trabajo de la madera procedentes de Izana y Langa de Duero (siglo I a.C.). (Según Barril 1992)

123. Población por grupos de edad y sexo a partir de los análisis antropológicos de las necrópolis de La Yunta (1) - según los datos de las cuatro primeras campañas publicadas y con indicación de las sepulturas «ricas» (con más de cinco objetos) - y Pozo Moro (2). (Según García Huerta y Antona 1992, modificado (1) y Almagro-Gorbea 1986b (2)). Población comparada por grupos de edad (3) de la necrópolis celtibérica de La Yunta (según García Huerta 1991b) con la ibérica de Pozo Moro (según Almagro-Gorbea 1986b) y la romana de Segobriga (según Almagro-Gorbea 1995b)

124. Jerarquización de las ciudades en el Valle Medio del Ebro: 1, ciudades de época ibérica; 2 , ciudades que perduran tras los acontecimientos cesarianos; 3, idem a partir de Claudio. 2-3: A, perduran; B, sin datos; C, desaparecen. (Según Burillo 1980)

125. 1-2, personajes danzando. 3-4, supuestas representaciones de divinidades procedentes de Numancia. 5 , representación bifronte del santuario de Peñalba de Villastar. Representaciones pintadas (1-3), modeladas en arcilla (4) y grabadas sobre roca (5). (Según Wattenberg 1963 (1 y 4), Taracena 1927 (2), Romero 1976a (3) y Cabré 1910 (5))

126. 1, escenas de sacrificios sobre cerámica griega (a-b) y sobre un vaso de Numancia (c); 2 , presencia de restos faunísticos en varias necrópolis celtibericas. (Según Meniel 1992 (a-b) y Wattenberg 1963 (c))...... 
127. Inutilización intencionada de armas (espadas, puñales, puntas de lanza, soliferrum y pilum) y otros objetos, como tijeras y elementos para la sujeción del tocado.

128. 1, representación pintada de un posible sacerdote (?) en un vaso de Arcobriga; 2, el mundo funerario celtibérico. (Según Aguilera 1909 (1) y Burillo 1991a (2))

129. 1, escena de un vaso numantino con guerreros muertos devorados por buitres; 2 , estela de Zurita; 3 , estela de «El Palao» de Alcañiz; 4, monumento de Binéfar; 5, friso de cabezas humanas aplicadas y aves rapaces pintadas de una urna de la necrópolis de Uxama. (Según Wattenberg 1963 (1), Peralta 1990 (2), Marco 1976 (3-4) y Cabré 1915-20 (5))

130. Numancia: 1, localización de restos humanos en la ciudad; 2, plano de las excavaciones llevadas a cabo en el ángulo de la manzana XXIII (a) y sección vertical de la habitación $n^{\circ} 4$ (b). (Según Jimeno y Morales 1993 (1) y Taracena 1943 (2))

131. Escritura celtibérica. (Según de Hoz 1988b)

132. Distribución geográfica de la epigrafía celtibérica, exceptuando los hallazgos en zonas alejadas de la Celtiberia (Sur de Francia, Ibiza, Extremadura y Portugal). (Según de Hoz 1988b)

133. A, bronce de Botorrita 1. B, téseras y tablas de hospitalidad, con indicación de sus relaciones geográficas. (Según Maid 1993 (A) y Almagro-Gorbea y Lorrio 1987a, modificado y actualizado (B)) ........................

134. El bronce de Botorrita 3. (Según Beltrán, de Hoz y Untermann 1996)

135. Bronce de Luzaga (1) y bronce «Ŕes» (2). (1, según Ortego 1985, modificado a partir de Gómez Moreno 1949 y fotografía; 2, según Burillo 1989-90)

136. 1, bronce de Cortono. 2, tésera de Arekorata, procedencia desconocida. 3, campamentos de Numancia. (Según Fatás 1985 (1), Burillo 1993a (2) y Schulten 1927 (3)

137. Téseras de hospitalidad. (Según Fernández-Guerra 1877, Almagro Basch 1982, Gómez Moreno 1949, García-Merino y Albertos 1981 y Tovar 1983, anverso dibujado sobre fotografía)

138. Téseras de hospitalidad: 1 y 4, procedencia desconocida; 2, Belorado; 3, Palenzuela; 5, Monte Cildá (1, según Gómez Moreno 1949 (reverso) y Romero y Sanz 1992 (anverso, dibujado sobre fotografía); 2, según Romero y Elorza 1990; 3, según Martin Valls 1984; 4, según Marco 1989; 5, según Peralta 1993; 6, según García Garrido y Pellicer 1984 (reverso) y Almagro-Gorbea y Lorrio 1992 (anverso, dibujado sobre fotografía))

139. A, situación de las ciudades que emiten moneda en la Celtiberia y zonas aledañas. B, Monedas (unidades y divisores) celtibéricas y del Alto Ebro. (A, según Domínguez 1988)

140. Numancia: 1, grafitos y signos sobre cerámica celtibérica y común romana; 2 , presencia de los diferentes signos registrados sobre cerámica celtibérica (A) y sobre terra sigillata y cerámica común romana (B). (Según Arlegui 1992a)

141. 1, tesoro de Monsanto da Beira; 2, signos sobre un dado de piedra arenisca procedente de Numancia; 3, grafito sobre fusayola de Arcobriga; 4 , inscripción rupestre de carácter religioso de Peñalba de Villastar. (Según Gomes y Beirão 1988 (1), Arlegui 1992a (2) y Gómez Moreno 1949 (3 y 4)

142. 1, inscripciones sepulcrales. (Según Gómez Moreno 1949, P. Beltrán 1972, Albertos y Romero 1981 y Palol y Villela 1987)...

143. Diagrama de correlación entre la Arqueología, la Lingüística, las fuentes históricas y la cronología del mundo celtibérico

\section{TABLAS}

Tabla 1. Evolución de los ajuares militares de las necrópolis del Alto Tajo-Alto Jalón (vid. Apéndices I y II) ..

Tabla 2. Evolución de los ajuares militares de las necrópolis del Alto Duero (vid. Apéndices I y II) 